\title{
Fishing for a sense of cultural identity and place
}

\author{
Elaine O'Driscoll-Adam
}

Department of Geography, UCC

\section{Introduction}

A strong sense of identity and place attachment has always been a characteristic of fishing families. Originally from a fishing family I identify myself with this particularity which engenders a distinctive relationship with the sea. Cultural geography is very much focused on place and how people 'live their lives' in particular places. How people develop attachments to specific places is a key element in cultural geography. While much of the research conducted on fishing communities to date has focused on policy frameworks and its economic importance, the cultural and social dimensions have largely been overlooked. Fishing not only provides an important source of food and employment but is a way of life for many inhabitants of coastal communities and as such is an essential element of maritime culture. It is understood that the seas and oceans make up 70 per cent of the earth's surface and almost 60 per cent of the world's population live in coastal areas. Yet people seem to struggle to comprehend this vast space in which fishers and their families attach meaning and construct their identity. Nevertheless, traditions are inevitably challenged in a globalising world; contemporary fishing families appear to engage in a changing discourse. Therefore, this study explores the cultural life of two fishing communities and their relationship(s) with the sea. It will consider how these relationships have changed over time and the processes that have underpinned these changes. It is essential to acknowledge the productions of identity and sense of place in fishing communities as the lives of inhabitants are very much linked to the complex entity of the sea. Located on the Western fringe of Europe Castletownbere and Le Guilvinec fishery harbours have been chosen for this study. These two communities share similarities however it is of interest to look at differences between both sites and what factors generate these variations.

\section{Remembering the past in order to identify with the present}

Fishing is perceived as an ancient practice; traditionally people living in coastal areas often made a livelihood out of this way of life. Certain maritime archaeologists maintain that people have used the sea as a source of identity and belonging for centuries; identity was socially and culturally constructed but also created by the routines of everyday 
life. Not only did the physical locality of these coastal communities help forge their local identities, the sea also brought external influences. Historically, cultural values and traditions provided a sense of identity to coastal inhabitants thus shaping these places. A strong sense of identity is frequently observed among fishers which tends to generate a strong sense of place. Society has considerably changed since historical times however many fishers will still argue that they are continually being detached from wider public life due to the amount of time spent at sea. Fishing communities have strong links to the sea that span generations; fishing can best be understood as a way of life rather than a means of economic income and it defines fishers' identities as individuals, households and communities. Below are some of the direct quotations from fishermen and their spouses that I interviewed.

'I couldn't live anywhere away from the sea. When you're born and reared near it, it becomes very much part of your life.'

'... it's a way of life without a doubt.'

'Fishing is in the blood. It's part of who you are. It's passed on from generation to generation.'

'Fishing is what I've always wanted to do ... I chose my path from a very young age.'

'My father and grandfather were fishermen ...'

Through single interviews and focus groups it became apparent that these coastal residents were attached to their community so much so that they experienced a sense of longing when away from the sea for any length of time. All those whom I interviewed admitted to spending their holidays in coastal locations. Fishermen's spouses confess that even on holidays their husbands tend to seek out the local fishery harbour.

'... I found him mending a net with a local fisherman; neither of them spoke each other's language...'

Fishing communities provide a sense of place that is often steeped in maritime heritage while traditions and local knowledge are intergenerational. Nonetheless, it is important to acknowledge that not all members of the same community share the same sense of place; identities are constantly being renegotiated. Although the physical environment can influence demeanour and shape identity, certain inhabitants admitted to feeling no attachment to fishing or to their environment. In contrast, it appears that fishers' attachment to their physical surroundings provides them with a sense of place and identity. Their daily engagement with the sea connects them with nature thus making them aware of both its bounty and misfortune.

\section{Symbols as part of identity and place attachment}

Individual identity is important to the formation of the collective. Many scholars assert that strong individualism sustains collective action. However, community does not auto- 
matically mean the same thing to all of its members. Although most fishing communities are dependent on the industry for its existence, fishing families and non-fishing families tend to experience community in very different ways. The lived experiences of each individual inhabitant are shaped by their interaction with other community members. Symbols forge how people experience identity and sense of place. Fishing communities have a multitude of symbols both visible and invisible such as fishing vessels, nets, fishermen's mass, fishy smells and the cawing of gulls. One particular resident remarked that the fishy smell around town signifies that the fishing industry is doing well. Others testified that events united the community and it is the coming together of community members in the various rituals and festivals that shapes one's collective identity and gives meaning to place. Therefore it is in practice that symbolic value is produced and reproduced. Several fishermen that I interviewed would agree that the Fishermen's Mass and the Blessing of the Fleet are two important events in the fisherman's calendar. Some declaring that 'they wouldn't miss it for anything' and others maintaining that they would 'transmit this tradition to their children.' In addition, fishermen discussed the importance of other members of the community attending the Fishermen's Mass as an acknowledgement to their livelihood. Fishing and coastal communities remain quite distinctive to communities inland; a sense of belonging together that strengthens the notion of collective identity. Some academics assert that there is a strong sense of identity and place attachment to coastal areas as place can serve as both a geographical and a social expression. For instance, a fisherman's daughter asserts that 'there's an infinity with other fishing people ...' Fishermen become acquainted with other fishermen throughout the country. There is a strong sense of shared identity amongst fisher society.

\section{Methodology: An ethnographic approach}

Places mean different things for different people; therefore, it is important to acknowledge the depth and complexity with which people construct meaningful relationships to their surroundings. An ethnographic approach accordingly seeks to explore and understand the meanings that people in particular places give to their everyday lived lives. It involves an engagement of the researcher with the people and place of study through immersion over a period of time. This qualitative approach provides a methodology that is highly suited to achieving the objectives of this research project and facilitates an in-depth exploration of both fishing communities. Furthermore, it provides an understanding of individual and collective lived experiences and focuses on direct contact with people therefore it is essential to create respectful relationships with all those involved in the research study. In practice, the concurrent use of qualitative methods such as participant observation will take the form of field notes, diary, photographic and video work. Interviews and focus groups also provide a comprehensive insight into the lives of these coastal inhabitants. Participant observation is central to this process as it allows me to observe, record and 
interpret the lived experiences of women and men. The process consists of visits to each site for a period of two to three months to provide an experiential representation. Fieldwork in Castletownbere was conducted over a cumulative period of three months. As per the methodology, this visit involved detailed recordings of the community. The interview phase has been completed with twelve in-depth interviews with active and retired fishers (eight ashore and four at sea) and a further five with non-fishing inhabitants. Two focus groups, each consisting of six participants, were carried out with women from fishing households. It is easier to engage with fishermen on an individual basis rather than through a focus group as their time ashore is precious. Conducting in-depth interviews permits participants to describe their lived experiences in their own words. Participants are recruited via contacts made during fieldwork. Potential participants are fully informed about the research, its aims and the procedures involved prior to making any commitment to an interview. Qualitative research is never linear and therefore overcoming obstacles at the initial stage of the fieldwork will facilitate conducting further investigation.

\section{Conclusion:}

The past plays an important role in the construction of both collective and individual identities. While a great deal of research has focused heretofore on the policy and economic impacts on fishing communities this research, using an ethnographic methodological approach, engages the experiential aspects of lived lives of both men and women and should provide a rich source of data to explore fishing communities in a much more in-depth and qualitative way. In some coastal areas fishermen are first generation therefore their identity as fishers gives them and their families a rootedness in their community. The physical environment provides fishing communities with a sense of place and identity moreover fishing is an important part of a town's heritage. It is vital that the younger members of society are aware of the connection fishing has to the past via skills that are handed down through generations; skills that cannot be learned in a textbook, however, training facilities are improving and schools are necessary especially when it comes to safety at sea. Since the arrival of modern technology fishing traditions are becoming part of an inherent past. Young members of society are born into the age of information technology and so the cultural heritage of fishing is on the decline. With the decline of cultural heritage comes the quest for a new sense of identity; individuals and groups alike need to feel a sense of belonging and rootedness thus providing greater self-esteem. Fishing, once a challenging occupation associated with freedom and independence, is becoming part of an industry that is in severe decline and that is frequently linked to stress and pressure. These changes have a negative impact not only on the fishermen still involved in the industry but they have repercussions for the wider community. It is important not to allow these fishing communities to decline. By exploring the cultural geographies of these communities this research sets out to redress a gap in the literature through methods such as participant ob- 
servation, individual and group interviews. It is important to capture as much knowledge and archive it for future generations lest it be forgotten.

Special thanks to my supervisors Dr John Crowley and Mr Ray O'Connor and colleagues for their continued support 